\title{
A Critical Overview of Plato's Epistemology in Dialectic of Meno
}

\author{
Wadigala $S^{*}$ \\ University of Peradeniya, Srilanka
}

*Corresponding author: Samitharathana Wadigala, University of Peradeniya, 190 Botley

Road Oxford OX2 0HW, Sri Lanka, Tel: +44763290467; Email: samitharathana23@gmail.com

\section{Conceptual Paper \\ Volume 4 Issue 1}

Received Date: January 07, 2021

Published Date: January 29, 2021

DOI: $10.23880 /$ phij-16000162

\section{Abstract}

Plato's epistemology precisely seems that a prospective analysis of human knowledge and virtue. The dialectic of Meno often has made up several attempts to arrive at rather intellectual and ambiguous complexes. It worked on the following critical issues over the dialogue. Mainly, the methodology of recollection and forms, immortality of the soul, concepts of real and reason have crucially discussed there. In particular, the above theoretical approaches have fundamentally based on virtue and knowledge. Otherwise, a few technical terminologies have been utilized continuously in the Meno like, 'epistêmê,' 'doxa.' The Meno's Paradoxa could stimulate subjective morphemes tremendously. Meno's epistemology's succinct scope is that the contrasted conversation is constructed by between metaphysical matters and facts of the knowledge, belief, or real opinion and other inevitable, formative elements during the acquisition of sensual perception.

Keyword: Epistemology; Meno; Knowledge; Virtue; Belief

\section{Introduction}

Here it would be hopeful to discuss in contrast epistemology of Plato's Meno. This brief study ought to be revealed the contextual critique just towards only Meno depicts Phaedo and Theaetetus, which were the most significant dilemmas of Plato. Primarily, in the Meno and Phaedo, Plato has engaged with the theory of recollection, the theory of forms, the immortality of the soul, and the concepts "true opinion/judgement" and "an explanation of the reason why" to illustrate a complete epistemological system (Sheng 2015, 1). Plato's Epistemology seems constructed on something he interprets epistêmê, often translated 'knowledge' (Matthews 1972, 13). ${ }^{1}$ In the Meno,

1 "Plato's epistemology has a number of starting points, spans a vast array of topics problems, and crosses and crisscrosses with many. In the Charmides (1676) questions about the nature of temperance lead into the question whether it is possible for knowledge to be itself an object of knowledge and, if so, whether a man who has it will know what he knows, or only that he knows." there are making some coherent differences between knowledge and belief. It does mind it has indeed appeared as a central interrogative fact here. Socrates and Meno arrive at two different hypotheses: in the first part of the dialogue, that virtue is knowledge and can therefore teach; in the second, that it is the valid, reliable opinion and can therefore be acquired only by divine inspiration (Stone 2010,1). Thus, the Meno's eristic dilemma circumvented a few intellectual aspects and attempted to consist of some epistemological issues. Insofar it looks forward to analyzing how the Meno could be in progress theory of knowledge.

\section{Discussion}

\section{What is Epistêmê or Epistemology?}

At the whole dialogue of Meno, Plato exclusively used the technical terminology of 'epistêmê.' However, it was always with some another morpheme called 'doxa' (Moline 


\section{Philosophy International Journal}

$1981,191){ }^{2}$ So this has conventionally been recognized and interpreted as 'Meno's Paradoxa' by the post-commentators (Suzuki 2011,2). In the Meno, the proper answer would seem obvious: episteme or epistemology is the knowledge utilizing virtue that can teach. However, the platonic dialogues link up with the theory that there are unchanging and eternal forms, which are the objects of knowledge, during the many controversial perceptible particulars. It might also contrast with belief. Then the epistemology has been in a contrasted conversation between knowledge and belief. Herein taking a few passages from the Meno:

- More valuable than Doxa (Meno 97d, Republic 476e)

- Harder to achieve than Doxa (Meno 85c-d) (Moss 2020: 1)

By the above facts, it seems, of course, some more striking similarities on epistêmê. It does mind it is not a surprise to knowing that episteme is knowledge. The contemporary epistemologists tend to look at Plato as the founder of the discipline. Moreover, even as the author of one of the dominant knowledge theories, as justified true belief (Armstrong 1973, 137). ${ }^{3}$ Plato says about epistêmê may be rather difficult to reconcile with the knowledge as it is a variant topographical context. For some examples:

- Requires reasoning out of the cause or explanation (aitias logismos, Meno 98a)

- It is more than a well-grounded true belief (Meno 85c-d) (Burnyeat 2015, 23) ${ }^{4}$

- Cannot be transmitted by testimony (Theaetetus 201c, Meno passim, Rep. 518b-c) (Moss 2020, 2)

These are the several clues which do indicate the epistemological configures in Plato's Meno unavoidably. Now it has been a critical reason to concerning epistêmê in together with knowledge and belief.

In particular, Plato has acutely concerned with at least a few of the following philosophical approaches toward epistêmê or epistemology in Meno (Matthews 1972). ${ }^{5}$

- How could it be different between knowledge and belief?

- Are our knowledge and belief incompatible?

2 Alternatively, he contrasts episteme, pronêsis, gnosis, Sophia, noêsis, or nous with Doxa or with Pisits. Plato almost always seems to treat the various terms for the superior category as equivalent.

3 If it would want many more instances which calls Meno 87-8 the "first recorded occurrence" of the "classical analysis of knowledge," see,

Armstrong, D. M. 1937. Belief, Truth and Knowledge. Cambridge: Cambridge University Press, 137.

4 See, Burnyeat 1980, 187 for an argument that the slave's true Doxa at the end of the discussion is, by modern standards, justified; cf. Schwab, 2015, 23.

5 This sharp critique is of Dr. Gwynneth Matthews (St Anne's College, Oxford, 1972). According to his analysis on Plato's epistêmê, dilemmas could draw very hard arrivals in terms of the objects, effects of each, relative stability, security and comprehensiveness, and so far.
- Is knowledge by acquaintance, or is the object of knowledge necessarily complex?

- If knowledge is concerned with the case, can a belief be concerned with what is not the case?

- How do we arrive at knowledge as distinct from belief?

\section{The Key Contradictions between Knowledge and Belief}

The Meno mainly shows that Plato has convinced a couple of issues on this matter. (1) Getting tried to take a position on behalf of belief in between perfect knowledge and blank ignorance or sensory illusion (2) Getting tried to draw up criteria to differentiate between knowledge and true belief (Matthews 1972, 14-15). Here the knowledge and belief should be identified by themselves in verifying the multiple branches occupied. It is possible to perceive and have beliefs about a pair of sticks, whereas although supported to 'recollection' by particulars, it is occurring the mind alone that it already knows equality and the equality there may be between sticks, gradually with other forms and forms-in-objects. ${ }^{6}$

Knowledge of forms recollected and unlike belief. ${ }^{7}$ That links the ability to give an account of what is known. The recollection theory, which figures large in the Meno and Phaedo, is near contributed to Plato to above intradistinction. It is between necessary and contingent truths and the intra-distinction between knowledge and belief he aligned with it (Fine ([2009]-2010, 4). ${ }^{8}$ It did not pursue in later dialogues, except the present acquisition of knowledge that Plato considers always.

Particular forms or images of knowledge is indeed typically distinguishable from the belief by reference to their different objects and material facts. Then knowledge deems as necessarily true. In terms of ontological differences between forms and particulars, timeless truths and shifting

6 Nevertheless, Vlastos (1985) and Woodruff (1990) say that others have argued, and Plato has in mind "logically certain knowledge," or "craftexpertise." They have found the word epistêmê often translated as 'Science.' It is neither knowledge nor belief. It can see for more examples Bosanquet (1895), Jowett (1908), Taylor (1926), Shorey (1930), and Hackforth (1958).

7 But here Chuanjie Sheng (University of Leeds, 2015) says that the soul can only recollect knowledge in the sensible world, and "learning is recollection" (Meno 81c-86b, Phaedo 72e-73a). If so, someone who does not know about something has within himself a valid opinion about that thing that he does not know (Meno 85c).

8 This raises the important question of what it is that one recollects. On the model of serial reminding, one recollects literally everything that one finds out by any kind of investigation, and everything that one recollects one has previously experienced.

For here, it is possible to access the following website: www. oxfordhandbooks.com. 


\section{Philosophy International Journal}

contingencies, and corresponding different states of mind, but also in terms of a systematic body of knowledge, hierarchically organized (Matthews 1972, 16-17), (Cornford 1935, 154-162). ${ }^{9}$ There seems no room left for Meno's slaveboy coming to know what he now rightly believes nor much room for being reminded of equality by seeing equal, or unequal, sticks. Plato is as ruthless with his argument as with his prisoners. According to Meno's dialogues, belief is at most the beginning of a long trek, which will take one through all known and foreseeable mathematics towards the philosophical goal and knowledge must be of what timeless and changeless, and must also have a particular starting point (Majeed 2014, 1), ${ }^{10}$ (Matthews 1972, 16-17).

\section{The judgment of Virtue | Virtue as Knowledge?}

Here the conversation of virtue would seem like the most prominent and controversial argumentation fact undoubtedly. The reason for such a dilemma may probably be the necessity of knowing and verifying what virtue is. Based on the Meno, first at foremost, it should precisely be known that (1) what virtue is and (2) what teaching is (Stone $2010,3)$. Socrates observes that the question 'Is virtue teachable?' cannot be answered until one knows what one means by virtue. In getting tried to answer the question, Meno a priori says a different approach to every individual or separate groups of people-men, women, young, old, and so far. The Meno remarks that justice and temperance for all humankind are necessary to indicate that at least all truth must be based on and comprehend the 'quiet' moral virtues (Bluck 1961, 4-5) ${ }^{11}$-a hint as to the nature of virtue which Meno should have followed up.

Meno's eristic dilemma may divide into the following synthetic overview. It does mind would help make comprehension of Meno's epistemology in many perspective ways (Bluck 1961). ${ }^{12}$

- The question 'Is virtue teachable?' raises the foremost

9 For more details of the distinction between knowledge and belief, it can see Cornford, F. M. 1935. Plato's Theory of Knowledge. London: Macmillan, 154-162.

10 The Question of what knowledge is about or what it means to know often ends up as one of whether or not the knowledge of something, indeed, of all things can teach. Some of the most insightful responses to these questions in ancient Greek philosophy can find in the intellectual context between the Sophists and Plato in the 5th century BC.

It can also access the following website here: http://dx.doi.org/10.4314/ ujah.vl5il.l.

11 For a much fuller discussion of the unity of virtues, it can see below. Bluck, R. S. 1961. Plato's Meno: Edited with Introduction and Commentary. Cambridge: Cambridge University Press, 4-5.

12 That is appropriately done by Dr. R. S. Bluck, University of Manchester, 1961. question 'What is virtue?' Then several attempts are made to define virtue.

- The question 'How can you look for something you do not know, or organize it if you find it out?

- Meno again asks, 'Is virtue teachable?' Socrates undertakes to investigate the question utilizing hypothesis, a method used by geometricians: Let us suppose that virtue is a kind of knowledge. If it is, it will be teachable; otherwise, it will not. However, virtue is knowledge. Therefore virtue is teachable.

- Socrates suggests that there is an objection to this conclusion. If a thing is teachable, there ought to be teachers of it. Nevertheless, there are no teachers of virtue. Therefore virtue cannot be reachable after all.

- Virtue is not knowledge. But 'true belief.' It is not teachable.

The interpretation of the dialogue is now described in detail and in a succinct way. It does help define the matter of virtue, whether as a piece of knowledge or not (Hamilton and Cairns 1961, 353). ${ }^{13}$

So now, if virtue is knowledge, it can precisely be taught. Also, one person can make other virtues by imparting some knowledge to them. It is frequently engaging and entangling what virtue is? Virtue is a moral, right, and beneficial rather than harmful (Stone 2010). ${ }^{14}$ The virtue manipulates us towards correct, meritorious, and moral deeds in avoiding violent and cruel habits. Of course, if virtue is knowledge, to teach virtue is to teach that virtue is knowledge. If Socrates can teach Meno what virtue is, he can teach him virtue. However, Socrates teaches Meno that virtue is knowledge; therefore, it can be taught (Brown 1986, 387-404). ${ }^{15}$ Per Meno's dilemma, the actual demonstration of it is, virtue is knowledge. Here Meno would mind agreeing with virtue as beneficial, meaning per as desirable. So he has proposed a couple of such purported morals (Stone 2010, 6):

- Bodily (Health, strength, beauty, and wealth)

- Psychic (Temperance, justice, courage, teach-ability, memory, magnificence)

Meno has acutely suggested these cosmopolitan facts as

13 "The last part of the dialogue is taken up with Socrates' demonstration and Meno's reluctant argument that virtue is not taught anywhere so that is not knowledge which can be and is taught. No further definition is attempted, but Socrates' conclusion, characteristically Greek, is that if ever there could be a man who in addition to being virtues knew what virtue was and could teach it, he would be among other men like a reality among fitting shades."

14 Abraham D. Stone (2010) again says that to know that something is virtue will be to choose to have that thing, rather than not to have it: to choose otherwise, under those circumstances, would be knowingly to choose the evil.

15 For a much fuller comprehension of the above, it can see Klein's Summery (Commentary, 36-7) with also Truesdell S. Brown. (1986), "Menon of Thessaly," 387-404. 


\section{Philosophy International Journal}

the main 'parts of virtue.' Consequently, Meno has recognized threefold claims, which, if virtue is knowledge, have radical and utilized implications (Stone 2010, 10).

- Knowledge is available to any human being

- All knowledge forms one whole

- Knowledge can teach

On the contrary, It would feel these threefold claims supposedly follow from Socrates' theory that learning is recollection. Whereas Socrates is not much sure about the sharpen critique of this theory. He is almost sure about the utilized consequence of taking knowledge and teaching to have the claimed nature. Thus Meno's argumentative facts on virtue as knowledge or true belief seem as much partially deal with the knowledge and its topographical proceeding.

\section{The Hypothesis | Virtue is Knowledge}

In Meno's question, 'Is virtue teachable?' which has ontologically made some recollection theory facilities, is still gaining a keen sense of knowledge (Desjardins 1985, 261-281). ${ }^{16,{ }^{17}}$ Then virtue should be a kind of knowledge, of course. It might agree that if virtue is a kind of knowledge, it must be teachable, and at the same time, nothing but knowledge thought. 'Virtue is kind of knowledge' is thus interpreted to be a limiting condition for 'virtue is teachable': if the condition is satisfied, virtue will be teachable, but if it is not, virtue will not be teachable (Bluck 1961, 17-18).

According to Meno's dialectic context, it has precisely affiliated with the assumption of knowledge, which is the only source of all goodness. Virtue can always make up us good and qualitative morality, of course. So virtue deems as profitable and advantaged. Whatsoever all things without knowledge may merely be creating some troubles, tragedies, and harms. There is no knowledge to make guidance for self and others, too, perhaps disastrous and harmful BeduAddo 1984, 1-14), (Hoerber 1960, 78-102), ${ }^{18}$ (Bluck 1961, 18). Knowledge alone can be arisen to them continuously profitable and advantaged. Virtue, therefore, must be hypothesized as knowledge or some forms (species) of knowledge. So given the genuine agreement, the virtue must

16 He has said here it is informing a more comprehensive glance over the whole of the dialogue, which inarguably requires a strenuous effort, and can "re-collect" answers to the main questions that posed at the beginning of the dialogue such as "what is virtue?" and whether it can be taught or not.

17 Lale Levin Basut (Yeditepe University) says in Meno's "Paradox": An Analysis of the Eristic Argument about that among those who were more interested in the general framework of the dialogue but not mainly and solely in the "paradox" itself. Moreover, it can see the following article for more comprehensive knowledge of the above.

18 Among many, see J. T. Bedu-Addo, "Recollection and the Argument 'From a Hypothesis' in Plato's Meno, The Journal of Hellenistic Studies, Vol. (1984), 1-14. And also you can see Robert G. Hoerber, <Plato's 'Meno"> Phronesis, Vol. 5, No. 2 (1960), 78-102. be knowable and teachable.

\section{Meno's Paradox}

Now it has been verifying Meno as a critical dialogue on epistemology in Plato's dilemmas. The Meno has tried to use epistemology to solving these ethical issues unavoidably (Irwin 1999, 143-170). ${ }^{19}$ Meno's paradox is the priority path to detangling ethical complications and establishing the community's virtual foundation. Meno's paradox inevitably prompts the change to taking epistemology as the fundamental foundation of ethics (Sheng 2015, 20). ${ }^{20}$ This paradox is the notable inauguration-point of the discussion of a series of questions about knowledge and knowing.

Meno occupies a couple of theories to solve Meno's paradox: - The immortality of the soul

- The theory of recollection (Learning is a kind of recollection)

So Meno's paradox is a severe turning-point of the whole intra-conversation since the transcendental relationship between epistemology and ethics. It also seems like a kind of skepticism is an essential query of epistemology.

Moreover, there are a vast number of cases between complete knowledge and complete ignorance. That is to say here, and there are three possibilities (Fine 1992, 200-226) ${ }^{21}$ : - Complete Knowledge

- Complete Ignorance

- Insufficient knowledge (in the sense of having something in mind but not fully knowing/having not enough knowledge) (Sheng 2015, 24)

More importantly, Meno has used some erroneous terms falsified by theories of logical linguistics in his paradox. The technical terminologies of "collecting information" or "how to understand a concept or notion when you have no concept in your soul/mind" rather than "learning inquiry" (Sheng 2015). ${ }^{22}$ That is the real disputable fact which is engaging at

19 Here, Irwin says that Meno's first definition of virtue satisfies "a metaphysical demand," whereas "Socrates adds an epistemological demand." It can see more details below the book.

20 'Considering three scholars' arguments, I will argue that the main problem of Meno's paradox is that Meno only considers the situation of the cognitive blank, i.e. when someone is completely ignorant or something (section 1.1)."

21 Here, Fine analyses Meno's paradox or eristic paradox deems as somewhat different when considering its reasonable and factual info. "Then she believes that Socrates' rephrase of the paradox is important for understanding Meno's paradox. She recasts Socrates' response as follows". That refers to Socrates' response. However, in Fine's article, there is no difference between Meno's paradox and Socrates's response, which is very distinctive from Scott's idea. Furthermore, it can see this article here.

22 "Chuanjie Sheng (University of Leeds, 2015) recognized this controversial issue. Moreover, he has explicitly made a diligent attempt to clarify this sharp argumentation here. As he says here, "Meno does not 


\section{Philosophy International Journal}

all movements in the Meno's paradox.

In contrast, Meno's paradox could attempt to query how would be understood at anything by a person in a cognitive blank. This critique has grown up a vast scope of Meno's paradox indeed. Socrates has employed the immortality of the soul and the theory of recollection to responding to this paradox. ${ }^{23}$ These twofold ideologies invented the cognitive blank, which not survives in human beings, of course.

\section{The Unity of Meno's Dialogue}

Finally, wherein can be recognized the real unity of Meno's dialogue? It does mind here the most crucial suggestion of the Meno as a whole is that all a priori knowledge or transcendental knowledge depends upon the theory of recollection (Bluck 1961, 43-44). Nevertheless, its early part was to define virtue. Then it is coming through on this account. It already revealed that the intra-connection between virtue and recollection might have corresponded in progress and multiple stages of the Meno. Here the best way for Meno was to recollect the nature of virtue in the method of epistemology. ${ }^{24}$ Obtaining an accurate account of Meno's virtue and knowledge could adequately bring out the Socratic definitions and philosophized proclaims toward knowledge theory. He could be understood and precisely apprehended outside the world of sense, objects of knowledge, partial awareness, association self-opinions, and interpreting learning methodologies (Bluck 1961, 45).

In particular, there are mainly three dimensions of the Meno's dialogue (Henderson 1956) ${ }^{25}$ :

- The epistemological search for definitions

- The discussion of virtue. (Whether it is teachable or not?)

- The theory of recollection with paradox (Stenzel 1964, 40-

correctly set is the question. That happens because Meno's understanding of the concept of "learning" is different from the three scholars' understanding of that notion. As the three scholars show, any learning or inquiry for Meno means the inquirer intends or is motivated to inquire about something.

23 However, for here, a possible Stoic answer maybe like this. Because the whole of nature has rationality, though different in degree, the soul could learn everything. That also cited from above.

24 That is perhaps all the more likely if Plato's recollection theory had based to any extent on what appeared to be Socrates' proceeding when he utilized.

25 Henderson GP (1956) says here that recollection and not virtue or the teachability of virtue, is the central theme of the Meno. Once we have had recollection described, we see that recollection to define. $X$ is the final real advance that can make in the discussion. That is true up to a point, but of course, Plato is interested in recollection primarily as the way by which virtue may learn; and the discussion of virtue based on true belief is vital for its own sake, and not merely as illustrating, by contrast, the value of recollected knowledge.
$44)^{26}$

On the contrary, this indicated by using a mathematical problem to illustrate recollection, although that is also useful here because (a) Meno himself no doubts knows the answer to the problem, while (b) Meno knows that the slave has never taught geometry (Bluck 1961, 45). However, Meno exclusively considers the main objective is to distinguish between a higher and a lower kind of goodness. Furthermore, 'the contributions of the dialogue to the theory of knowledge, the exposition of the doctrine of 'reminiscence,' and the method's principles are meant to be secondary to this main result (Tayler 1920, 145).

\section{Conclusion}

The hypothetical outline of this scholarly article on the epistemology of Plato's Meno could be summarized as follows: (a) the soul has seen knowledgeable all things on the earth and in the underworld, there is nothing which it has not learned. So the Forms are the objects of knowledge, (b) there are mainly a couple of reasons in the sensible world that cannot gain knowledge. However, only recollect it as the soul is influenced by the body, and the objects of recognition are always in flux (c) the soul can only recollect knowledge in the sensible world and "learning recollection" (d) this recollection will finally make the valid opinion become knowledge (Sheng 2015). ${ }^{27}$ In particular, this epistemological system's essential feature is that it has precisely rooted in the Forms. Here it has unavoidably emphasized the region beyond the sensible world; the soul could be acquired knowledge.

\section{References}

1. Armstrong DM (1973) Belief, Truth, and Knowledge. Cambridge: Cambridge University Press.

2. Bluck RS (1961) Plato's Meno: Edited with Introduction and Commentary. Cambridge: Cambridge University Press.

3. Cornford FM (1935) Plato's Theory of Knowledge. London: Macmillan.

\footnotetext{
26 But Stenzel has claimed that Plato initially limited his realm of Forms to ethical or quasi-ethical entities. His language often implies that it was due to a desire to enhance 'ideals.' Certainly, the individualization of the Form, combined with its 'separation,' caused many problems to arise, and we might tempt to attribute it merely to Plato's intuitive or visionary mode of thought and to say that the function of such Forms must have been to serve as ideals.

27 For here, it could refer Ph.D. dissertation of Chuanjie Sheng (University of Leeds, 2015) in proper.
} 
4. Desjardins R (1985) Knowledge and Virtue: Paradox in Plato's 'Meno'. The Review of Metaphysics, USA: Philosophy Education Society Inc 39(2): 261-281.

5. Fine G (1992) Inquiry in the Meno. The Cambridge Companion to Plato. Cambridge: Cambridge University Press.

6. Irwin T (1999) The Theory of Forms, Metaphysics, and Epistemology. Oxford: Oxford University Press.

7. Majeed HM (2014) Plato's Theories of Knowledge and Education: An Examination of the Interpretations of Cloete and Agyemang. UJAH: Unizik Journal of Arts and Humanities 15(1): 1-17.

8. Matthews G (1972) Plato's Epistemology and Related Logical Problems. Oxford: St Anne's College.

9. Moline J (1981) Plato's Theory of Understanding. University of Wisconsin Press, USA.

10. Moss J (2020) What the Ancients Offer to Contemporary Epistemology. Hetherington S, Smith N (Eds.), London:
Routledge.

11. Sheng C (2015) Plato's Epistemology: A Coherent Account in Meno, Phaedo, and Theaetetus. University of Leeds, UK.

12. Stenzel J (1964) Plato's Method of Dialectic. Russell \& Russell, USA.

13. Stone AD (2010) On the Teaching of Virtue in Plato's Meno and the Nature of Philosophical Authority. London: Robert Macehose \& Co Ltd Glasgow.

14. Suzuki Y (2011) The Underlying Paradox of Plato's Meno 80d5-e5. UK: University of Durham.

15. Tayler AE (1920) Plato: The Man and His Work. New York: Dover Publications, INC.

16. Edith H, Huntington C (1961) The Collected Dialogues of Plato: Including the Letters. Bollingen Foundation, USA.

17. Gail Fine (2009-2010) The Oxford Handbook of Plato. Oxford: Oxford University Press. 